\title{
Representações de conteúdo inseridas no plano de ensino de professores em formação continuada
}

Prado Kamila Ferreira; Zuliani Silvia Regina Quijadas Aro, Bombonato; Maria Terezinha Siqueira

\section{Resumo}

A partir de um curso com abordagem interdisciplinar contemplando as áreas: Química, Física e Ciências Biológicas, solicitou-se aos professores de Química a elaboração de Planos de Ensino, sobre o tema Equilíbrio Químico. O objetivo foi construir uma análise das representações de conteúdo (CoRe) no planejamento. A pesquisa realizada caracteriza-se como qualitativa descritiva e a análise foi realizada com base na análise de conteúdo. Inicialmente os professores apresentavam preocupação com relação à memorização dos conceitos pelos alunos. Ao final, pode-se perceber uma ligeira mudança no discurso dos professores e sua postura valoriza a compreensão dos conceitos relacionados ao conteúdo, e os conhecimentos prévios dos alunos como requisitos de aprendizagem.

\section{Palavras chave}

Formação de professores. Representação do conteúdo (CoRe). Conhecimento pedagógico do conteúdo.

\section{Objetivos}

A análise do Curso de Formação e Aperfeiçoamento de Professores realizado em uma universidade, em Bauru, São Paulo, Brasil embasou este trabalho. Um curso com abordagem interdisciplinar entre as áreas de Química, Física e Ciências Biológicas, onde aos professores de Química solicitou-se a elaboração de um Plano de Ensino, no início e ao final do curso, sobre o tema Equilíbrio Químico, a fim de construir uma análise das representações de conteúdo no planejamento das aulas sobre o tema. Inicialmente os professores apresentavam preocupação com relação à memorização dos conceitos pelos alunos. Ao final, sua postura foi modificada, da prática " decorativa" para a compreensão dos conceitos relacionados ao conteúdo proposto, enfatizando a importância dos conhecimentos prévios dos alunos e os requisitos de aprendizagem. Pode-se perceber uma ligeira mudança no discurso dos professores. 
Revista Tecné, Episteme y Didaxis: TED. Año 2014, Número Extraordinario. ISSN Impreso: 0121-3814, ISSN web: 2323-0126

Memorias, Sexto Congreso Internacional sobre Formación de Profesores de Ciencias. 08 al 10 de octubre de 2014, Bogotá

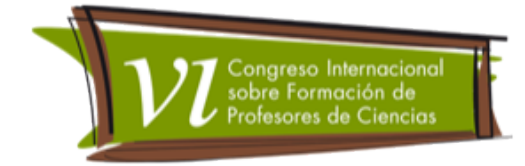

O presente trabalho tem por objetivo lançar um olhar crítico a uma proposta de formação produzida em uma universidade pública na cidade de Bauru, SP e foi realizado através da análise de uma das atividades realizadas num curso de formação continuada com os professores de Química. O foco de interesse foi a inserção das representações de conteúdo e sua avaliação no planejamento de uma aula sobre Equilíbrio Químico.

\section{Marco Teórico}

A formação inicial dos professores, atualmente, está longe da realidade escolar, enquanto isto os cursos de formação continuada tentam aperfeiçoar as práticas pedagógicas de professores, através das pesquisas, na tentativa de minimizar os problemas.

O Conhecimento Pedagógico do Conteúdo (PCK, da sigla em inglês "Pedagogical Content Knowledge") é considerado o conhecimento profissional específico dos professores. O PCK, segundo Shulman (1986) é o conhecimento da que aproxima aspectos do conteúdo ao seu processo de ensino. Ele tem sido considerado o melhor eixo teórico para examinar e compreender as habilidades de professores. O estudo do PCK de professores em diferentes momentos profissionais, seja na formação inicial, ingressantes na profissão, ou experientes, em formação contínua, visa trazer subsídios para a sua formação.

É possível considerar os planejamentos de aula como uma demonstração do PCK dos professores, na medida em que metodologia, abordagens teóricas, concepções pedagógicas, informações técnicas são associados ao conteúdo a ser ensinado.

A elaboração de um planejamento significativo envolve a escolha de objetivos gerais e específicos a serem alcançados, pontuar cada conteúdo disciplinar, levantar dificuldades conceituais, escolher estratégias e atividades didáticas, que minimizem as dificuldades, através da elaboração de avaliações adequadas aos objetivos (Villani, 1991, págs. 164-166). Estas competências e suas variações são apresentadas em exemplos de modelos de planejamentos.

Neste trabalho, adotou-se o modelo de Magnusson et al 11999, apud Fernandez, 2011, pág. 5) Seu modelo de construção do PCK é apresentado na FIGURA 1. Para o autor há interação entre o conhecimento dos professores e o conhecimento da compreensão dos alunos sobre Ciências, avaliação, estratégias instrucionais e conhecimento do currículo de Ciências moldando orientações para o Ensino de Ciências. 
Revista Tecné, Episteme y Didaxis: TED. Año 2014, Número Extraordinario. ISSN Impreso: 0121-3814, ISSN web: 2323-0126

Memorias, Sexto Congreso Internacional sobre Formación de Profesores de Ciencias. 08 al 10 de octubre de 2014, Bogotá

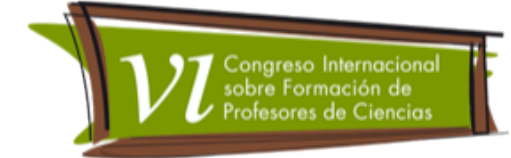

FIGURA 1. Componentes do conhecimento pedagógico do conteúdo. Fonte: Magnusson et al (1999 apud Fernandez, 2011, pág. 5)

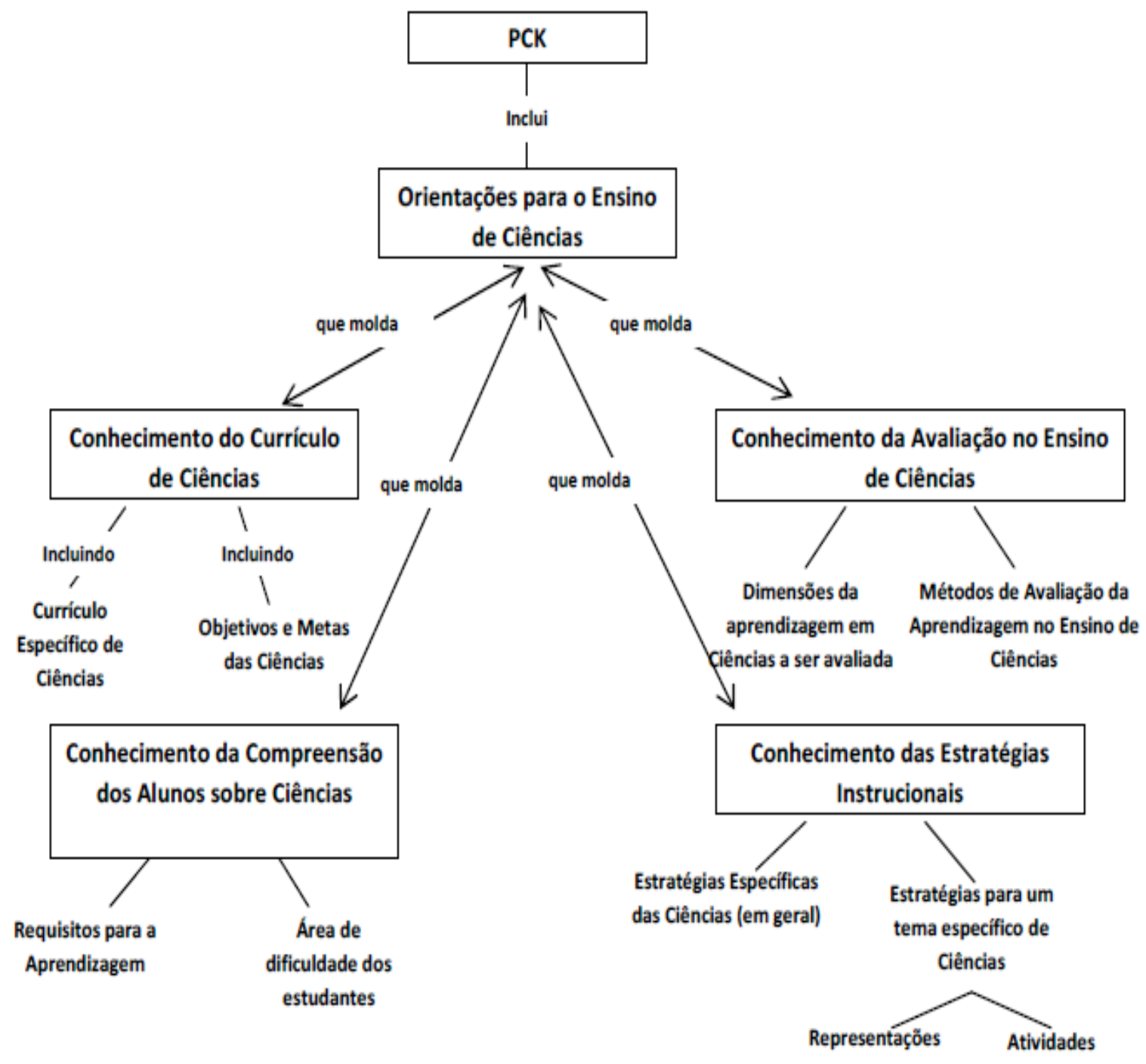

O PCK seria a transformação do conhecimento do conteúdo, da pedagogia e do contexto até uma forma distinta, a única forma de conhecimento que traria impacto na prática dos professores. O modelo não se preocupa com o desenvolvimento destes conhecimentos, mas sim como se transformam em PCK na prática docente, como conhecimento base para o ensino.

A pesquisa voltada para o PCK deveria refletir efetivamente na formação inicial e continuada de professores. A separação entre o conhecimento disciplinar e o conhecimento pedagógico, faz com que licenciados sejam formados com um conjunto de ideias e conceitos desconectados, devido à carência na construção de uma sólida base do PCK. A falta de capacidade de integrar conhecimentos disciplinares coerentemente com conhecimentos 
Revista Tecné, Episteme y Didaxis: TED. Año 2014, Número Extraordinario. ISSN Impreso: 0121-3814, ISSN web: 2323-0126

Memorias, Sexto Congreso Internacional sobre Formación de Profesores de Ciencias. 08 al 10 de octubre de 2014, Bogotá

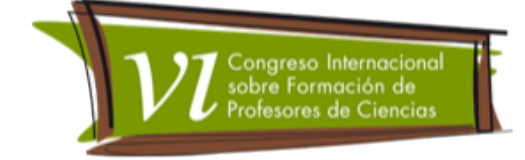

pedagógicos, gera decisões e ações pouco eficazes em sala de aula. Esta integração não se dá de maneira natural, e requer reflexão, preparo e tempo para o desenvolvimento por parte dos docentes. A reflexão do sujeito, licenciando ou professor em formação continuada, com relação ao seu próprio desenvolvimento profissional torna-o consciente da sua própria aprendizagem. Este trabalho tem por base esta reflexão.

\section{Metodologia}

Esta pesquisa classifica-se como pesquisa qualitativa descritiva, metodologia que busca descrever uma análise que se desdobra em uma parte documental e na utilização de instrumentos escritos para levantamento dos dados.

Os sujeitos desta pesquisa são dois professores de Química da Rede Pública Estadual, que lecionam há mais de dez anos, através de plataforma on-line.

Foi utilizado o Sistema SurveyMonkey, ferramenta de pesquisa qualitativa e quantitativa, disponível gratuitamente. Enviaram-se os links por e-mail aos professores que não se ausentaram das atividades a fim de tornar as respostas ao questionário válidas para análise. Dois questionários foram criados na plataforma em épocas diferentes do curso. Para o plano de aula final, o sistema não foi utilizado, uma atividade em sala foi realizada durante o horário do curso. Os professores foram identificados apenas com seu número de C.P.F. (Cadastro de Pessoa Física), para preservar suas identidades.

Para identificar os elementos de CoRe utilizamos a análise do conteúdo (Bardin, 1994) das seções do plano de ensino desenvolvido pelos professores e dos CoRe.

\section{Resultados}

A aplicação da atividade para a construção do Plano de Ensino teve como questão orientadora: " Utilizando as questões abaixo construa um plano de ensino para o tema Equilíbrio Químico levando em consideração as concepções dos alunos discutidas em nosso último encontro e o texto sobre a construção de atividades de ensino". Os dados das ideias dos professores estão apresentados na Figura 2.

A questão orientadora inicial foi mantida no Plano de Ensino Final, e os dados apresentados na Figura 3.

O Plano de Ensino Final foi realizado em grupo pelos professores, sendo que o professor 1 participou na elaboração do Plano de Ensino Final em um grupo, e o professor 2 em outro grupo. Os grupos tinham um máximo de cinco e um mínimo de três professores. 
Revista Tecné, Episteme y Didaxis: TED. Año 2014, Número Extraordinario. ISSN Impreso: 0121-3814, ISSN web: 2323-0126 Memorias, Sexto Congreso Internacional sobre Formación de Profesores de Ciencias. 08 al 10 de octubre de 2014, Bogotá

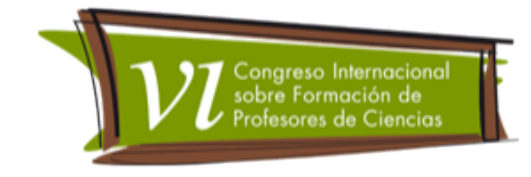

A confecção do CoRe foi realizada individualmente na plataforma on-line. Foi utilizado para estimular o raciocínio pedagógico do professor promovendo uma possível ampliação do seu PCK. As questões propostas bem como as respostas dos professores são apresentadas na Figura 4.

FIGURA 2. Plano de Ensino Inicial.

\begin{tabular}{|c|c|c|}
\hline & \multicolumn{2}{|c|}{$\begin{array}{l}\text { Conteúdo Específico: } \\
\text { Equilibrio Químico }\end{array}$} \\
\hline & \multicolumn{2}{|c|}{$\begin{array}{c}\text { Ideias/Conceitos centrais relacionados a } \\
\text { este conteúdo }\end{array}$} \\
\hline & Professor 1 & Professor 2 \\
\hline $\begin{array}{l}\text { O que você pretende que seus alunos } \\
\text { aprendam sobre este tema? }\end{array}$ & $\begin{array}{l}\text { Relacionar com o } \\
\text { cotidiano dos alunos. }\end{array}$ & $\begin{array}{l}\text { Conceitos } \\
\text { especificos. }\end{array}$ \\
\hline $\begin{array}{l}\text { Por que é importante para os alunos } \\
\text { aprenderem este conteúdo? }\end{array}$ & $\begin{array}{l}\text { Relacionar com } 0 \\
\text { cotidiano. }\end{array}$ & $\begin{array}{l}\text { Desenvolvimento } \\
\text { do conhecimento. }\end{array}$ \\
\hline O que mais você sabe deste conteúdo? & $\begin{array}{l}\text { Velocidade } \quad \mathrm{e} \\
\text { reversibilidade. }\end{array}$ & $\begin{array}{l}\text { Relação com outros } \\
\text { conteúdos. }\end{array}$ \\
\hline $\begin{array}{l}\text { O que você não vai ensinar, por } \\
\text { enquanto, aos estudantes? }\end{array}$ & Cálculos e fórmulas. & $\begin{array}{l}\text { Memorização de } \\
\text { equações químicas. }\end{array}$ \\
\hline $\begin{array}{l}\text { Quais são as dificuldades específicas } \\
\text { de aprendizagem relacionadas a este } \\
\text { conteúdo que os estudantes } \\
\text { apresentam? }\end{array}$ & $\begin{array}{lr}\text { Falta } & \text { de } \\
\text { memorização } & \text { em } \\
\text { conceitos. } & \end{array}$ & $\begin{array}{ll}\text { Falta } & \text { de } \\
\text { memorização } & \text { de } \\
\text { pré-requisitos. } & \end{array}$ \\
\hline $\begin{array}{l}\text { Quais conhecimentos você possui a } \\
\text { respeito do raciocínio dos alunos que } \\
\text { influenciam na sua prática docente ao } \\
\text { abordar este conteúdo? }\end{array}$ & $\begin{array}{l}\text { Indisciplina } \\
\text { alunos. }\end{array}$ & $\begin{array}{l}\text { Priorizar cálculos e } \\
\text { aplicações de } \\
\text { conceitos. }\end{array}$ \\
\hline $\begin{array}{l}\text { Quais sãos os outros fatores que } \\
\text { influenciam suas escolhas ao ensinar } \\
\text { este conteúdo? }\end{array}$ & $\begin{array}{l}\text { "Problemas" } \\
\text { alunos. }\end{array}$ & $\begin{array}{l}\text { Aplicabilidade dos } \\
\text { conceitos. }\end{array}$ \\
\hline $\begin{array}{l}\text { Que estratégias de ensino você } \\
\text { emprega ao ensinar este conteúdo? } \\
\text { Quais as razões para empregá-las? }\end{array}$ & $\begin{array}{l}\text { Demonstração } \\
\text { visual. }\end{array}$ & $\begin{array}{l}\text { Uso de gráficos e } \\
\text { imagens. }\end{array}$ \\
\hline $\begin{array}{l}\text { De que maneira você avalia a } \\
\text { compreensão ou as confusões dos } \\
\text { alunos acerca deste conteúdo (inclua } \\
\text { as prováveis respostas dadas pelos } \\
\text { alunos)? }\end{array}$ & $\begin{array}{l}\text { Dificuldade em } \\
\text { relacionar equilibrio } \\
\text { com variáveis. }\end{array}$ & $\begin{array}{l}\text { Dificuldade em } \\
\text { reação direta e } \\
\text { inversa, solução } \\
\text { saturada/insaturada. }\end{array}$ \\
\hline
\end{tabular}


Revista Tecné, Episteme y Didaxis: TED. Año 2014, Número Extraordinario. ISSN Impreso: 0121-3814, ISSN web: 2323-0126 Memorias, Sexto Congreso Internacional sobre Formación de Profesores de Ciencias. 08 al 10 de octubre de 2014, Bogotá

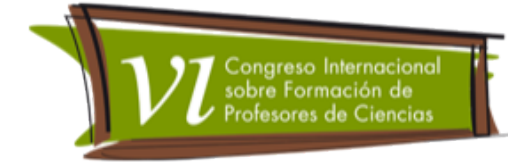

FIGURA 3. Plano de Ensino Final.

\begin{tabular}{|c|c|c|}
\hline & \multirow{3}{*}{\multicolumn{2}{|c|}{$\begin{array}{c}\begin{array}{c}\text { Conteúdo Específico: } \\
\text { Equilibrio Químico }\end{array} \\
\begin{array}{c}\text { Ideias/Conceitos centrais relacionados a } \\
\text { este conteúdo }\end{array} \\
\text { Professor l }\end{array}$}} \\
\hline & & \\
\hline & & \\
\hline $\begin{array}{l}\text { O que você pretende que se } \\
\text { aprendam sobre este tema? }\end{array}$ & $\begin{array}{l}\text { Compreender } \\
\text { situações de } \\
\text { equilibrio químico. }\end{array}$ & $\begin{array}{lr}\text { Conteúdos } & \text { sobre } \\
\text { cinética } & \text { química } \\
\text { como pré-requisitos. }\end{array}$ \\
\hline $\begin{array}{l}\text { Por que é importante para os alunos } \\
\text { aprenderem este conteúdo? }\end{array}$ & $\begin{array}{l}\text { Relação com o } \\
\text { cotidiano, processos } \\
\text { industriais, } \\
\text { comerciais e no } \\
\text { corpo humano. }\end{array}$ & $\begin{array}{lr}\text { Interferentes } & \text { na } \\
\text { velocidade } & \text { das } \\
\text { transformações } & \\
\text { químicas } & \text { no } \\
\text { cotidiano. } & \end{array}$ \\
\hline O que mais você sabe deste conteúdo? & $\begin{array}{ll}\text { Conceito } & \text { de } \\
\text { deslocamento } & \text { de } \\
\text { equilibrio. } & \\
\end{array}$ & $\begin{array}{l}\text { Velocidade das } \\
\text { reações, coexistência } \\
\text { de reagentes e } \\
\text { produtos. }\end{array}$ \\
\hline $\begin{array}{l}\text { O que você não vt } \\
\text { enquanto, aos estuda }\end{array}$ & $\begin{array}{l}\text { Conceitos e cálculos } \\
\text { de constantes de } \\
\text { equilibrio. }\end{array}$ & $\begin{array}{l}\text { Cálculos } \\
\text { constantes } \\
\text { equilibrio. }\end{array}$ \\
\hline $\begin{array}{l}\text { Quais são as dificuldades específicas } \\
\text { de aprendizagem relacionadas a este } \\
\text { conteúdo que os estudantes } \\
\text { apresentam? }\end{array}$ & $\begin{array}{l}\text { Relacionar } \\
\text { conceitos. }\end{array}$ & $\begin{array}{l}\text { Compreensão e } \\
\text { relacionar conceitos. }\end{array}$ \\
\hline $\begin{array}{l}\text { Quais conhecimentos você possui a } \\
\text { respeito do raciocínio dos alunos que } \\
\text { influenciam na sua prática docente ao } \\
\text { abordar este conteúdo? }\end{array}$ & $\begin{array}{llr}\text { Importância } & \text { de } \\
\text { relacionar com } & 0 \\
\text { cotidiano. } & & \end{array}$ & $\begin{array}{lr}\text { Importância } & \text { de } \\
\text { relacionar com } & 0 \\
\text { cotidiano. } & \end{array}$ \\
\hline $\begin{array}{l}\text { Quais sãos os outros fatores que } \\
\text { influenciam suas escolhas ao ensinar } \\
\text { este conteúdo? }\end{array}$ & Provas de seleção. & $\begin{array}{l}\text { Dificuldades em } \\
\text { concepções prévias e } \\
\text { provas de seleção. }\end{array}$ \\
\hline $\begin{array}{l}\text { Que estratégias de ensino você } \\
\text { emprega ao ensinar este conteúdo? } \\
\text { Quais as razões para empregá-las? }\end{array}$ & \begin{tabular}{|l|} 
Diversos \\
visuais.
\end{tabular} & $\begin{array}{l}\text { Recursos visuais e } \\
\text { pedagógicos. }\end{array}$ \\
\hline $\begin{array}{l}\text { De que maneira você avalia a } \\
\text { compreensão ou as confusões dos } \\
\text { alunos acerca deste conteúdo (inclua } \\
\text { as prováveis respostas dadas pelos } \\
\text { alunos)? }\end{array}$ & $\begin{array}{l}\text { Não conseguem } \\
\text { relacionar } \\
\text { conteúdos. }\end{array}$ & $\begin{array}{l}\text { Avaliação continua } \\
\text { com análise de } \\
\text { melhorias. }\end{array}$ \\
\hline
\end{tabular}


Revista Tecné, Episteme y Didaxis: TED. Año 2014, Número Extraordinario. ISSN Impreso: 0121-3814, ISSN web: 2323-0126 Memorias, Sexto Congreso Internacional sobre Formación de Profesores de Ciencias. 08 al 10 de octubre de 2014, Bogotá

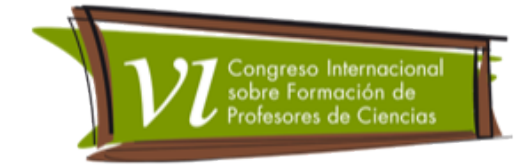

FIGURA 4. Dados CoRe.

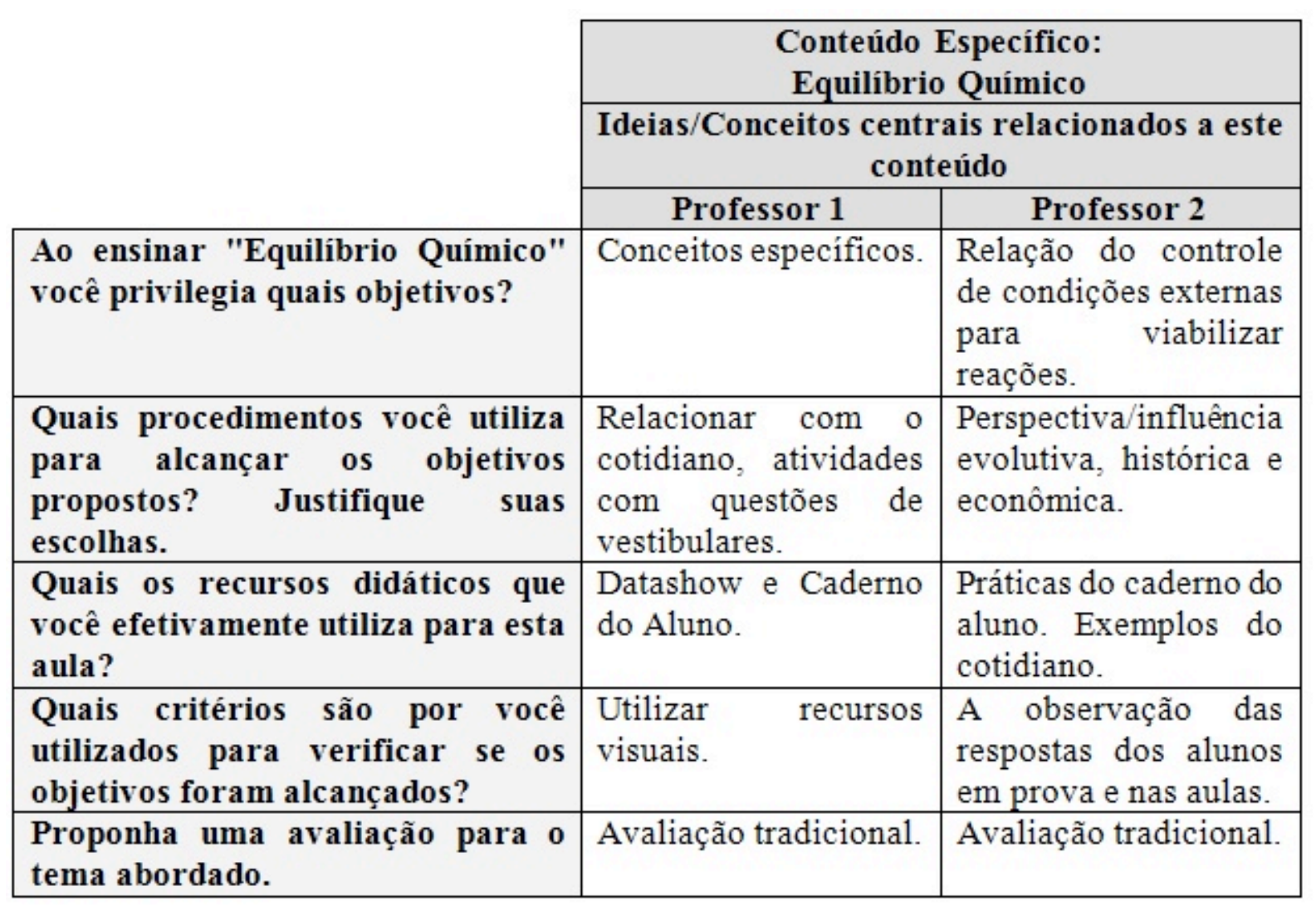

Para análise comparativa entre os Planos de Ensino e o CoRe, tomou-se por base o modelo de PCK, proposto por Magnusson et al (1999, apud Fernandez, 2011 , pág. 5), onde os conhecimentos base do ensino foram adaptados para os conhecimentos base do ensino de ciências. De acordo com análise comparativa entre o Plano de Ensino Inicial e o Plano Final, pudemos perceber que no início do curso os professores apresentavam preocupação com relação à memorização dos conceitos pelos alunos. Ao final, a postura dos professores foi modificada da memorização para a preocupação com a compreensão dos conceitos relacionados ao conteúdo de Equilíbrio Químico, enfatizando a importância dos conhecimentos prévios dos alunos e os requisitos de aprendizagem, inseridos por Magnusson et al (1999, apud Fernandez, 2011, pág. 5) no "Conhecimento da Compreensão dos Alunos sobre Ciência".

Como recursos didáticos os professores afirmam utilizar aulas com Datashow, atividades experimentais do caderno do aluno e exemplos do cotidiano. As atividades visuais foram citadas em todo o processo, caracterizando a crença 
Revista Tecné, Episteme y Didaxis: TED. Año 2014, Número Extraordinario. ISSN Impreso: 0121-3814, ISSN web: 2323-0126

Memorias, Sexto Congreso Internacional sobre Formación de Profesores de Ciencias. 08 al 10 de octubre de 2014, Bogotá

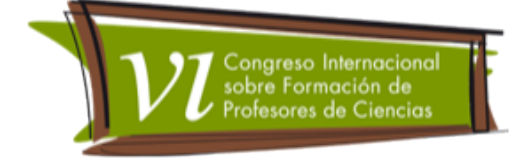

de que estas contribuem para um aprendizado mais significativo e rápido, pois atraem a atenção dos alunos, principalmente por não serem utilizados com tanta frequência na Rede Pública de Ensino. Isto pode ser interpretado como possível falta de conhecimento sobre outras estratégias pedagógicas específicas.

Os professores apresentavam preocupação com relação à memorização dos conceitos por parte dos alunos:

Ideia 1. "Falta de memorização em conceitos de molaridade, concentração, pressão, temperatura, fórmulas aplicadas e análise de tabelas/gráficos."

Ideia 2. "Falta de memorização de pré-requisitos (cinética, termoquímica e química inorgânica) e dificuldade em operações matemáticas. "

A postura foi modificada para a compreensão dos conceitos e para a importância de relacionar os conteúdos:

Professor 1.CoRe. "Promover um pensamento crítico, relacionar com o cotidiano, apresentar as reações utilizando Datashow (...) atividades com questões de vestibulares. "

Professor 2.CoRe. "Perspectiva/influência evolutiva, histórica e econômica, exemplos de reação em equilíbrio e fatores de influência, reações reversíveis e irreversíveis e equilíbrio dinâmico. ,'

O professor 2 reconhece a importância da continuidade no processo de ensino e de aprendizagem:

Professor 2. " As avaliações serão feitas durante todo o processo, escritas e envolvimento durante as atividades. Identificar as dificuldades ainda não superadas e elaborar propostas alternativas para saná-las. ",

Pelas afirmações pode-se dizer que houve uma ligeira mudança no discurso dos professore, podendo representar uma disposição real para mudança do ensino disposto a inserir o aluno no processo ensino-aprendizagem.

Os professores não atribuem as dificuldades de aprendizagem dos alunos aos problemas pontuais, como comportamento e educação familiar, e passam a atribuíla à condução do ensino e aprendizagem, e sua própria possibilidade de influenciar no processo. 
Revista Tecné, Episteme y Didaxis: TED. Año 2014, Número Extraordinario. ISSN Impreso: 0121-3814, ISSN web: 2323-0126

Memorias, Sexto Congreso Internacional sobre Formación de Profesores de Ciencias. 08 al 10 de octubre de 2014, Bogotá

\section{Conclusões}

Ao final do curso de formação continuada os professores mostraram maior interesse em desenvolver atividades visuais e experimentais com seus alunos, apresentando uma concepção positiva em relacionar Equilíbrio Químico ao contexto social, econômico e cultural dos alunos.

A metodologia do Ensino por Investigação não esteve presente nos planejamentos. Acredita-se que durante o curso e sua organização poderiam ter sido tomadas outras medidas, de forma a melhor trabalhar este ponto. Parece-nos, que os professores tiveram um início de desenvolvimento reflexivo sobre suas práticas pedagógicas.

De acordo com comparação entre o PCK proposto por Magnusson et al (1999, apud Fernandez, 2011, pág. 5) os professores realizam em seu planejamento interação entre o próprio conhecimento e o conhecimento da compreensão dos alunos sobre a Ciência. Pode-se dizer que os professores não demonstraram uma visão mais ampla sobre estratégias pedagógicas alternativas, uma vez que apesar de serem discutidas diversas destas estratégias durante o curso, elas não estão evidentes em seu planejamento.

\section{Referências Bibliográficas}

Bardin, L. Análise de Conteúdo. Edições 70, 1994.

Fernandez, C. PCK - Conhecimento Pedagógico do Conteúdo: perspectivas e possibilidades para a formação de professores. Anais VII ENPEC. Disponível em: http://www.nutes.ufrj.br/abrapec/viiienpec/resumos/R0370-1.pdf>. Acesso em: 06 jun. 2013.

Shulman, L. S. Those who understand: Knowledge Growth in Teaching Educational Researcher, v. 15, n. 2, 4-14, 2011.

Villani, A. Planejamento escolar: um instrumento de atualização dos professores de ciências. Revista Brasileira de Ensino de Física, v. 13, 164-166, 1991. 